\section{THE PRESENT POSITION OF ELECTRIC STEEL-MELTING.}

THE melting of steel by means of electricity has passed the merely experimental stage and become one of the commercial processes by means of which steel is manufactured for the market. It is not correct to say that it has emerged from the experimental stage, however, as not only this process of steel-making, but most other processes, are being continually experimented with and the results compared with one another by up-to-date and vigorous firms, not only for the new conditions that are always arising, but also for old and well-tried conditions.

A new demand arises or repeat orders come in, and the manufacturer must ask himself what kind of steel will best suit the purpose at the present time. Will Bessemer or open-hearth steel be most suitable to satisfy the demand, price, quality, and all other matters considered, and must it be acid steel or will basic do, or is it necessary or desirable to use crucible steel, or perhaps this new electric steel, to maintain or increase his profit or his reputation for certain goods? These are problems of daily occurrence; and although the difficulties of the manufacture of electric steel by various processes have been fairly well overcome, so far as making it to specification of chemical composition and mechanical tests is concerned, it is in connection with such questions as are indicated in the previous sentence that it is still in the earlier experimental stage. All other processes, however, are more or less under such trials until they become extinct. The point need not be laboured, for many examples will come to the mind at once, such as the comparative merits for various purposes of Swedish-Lancashire and Walloon iron, of mild steel and wrought iron, of acid and basic steel, and so on. The general impression gathered from much conversation with users is that the arc-furnace product from slightly impure materials, purified to Swedish standard, just about takes its place by Swedish open-hearth and Bessemer steels, and that the induction-furnace product skilfully made from pure materials equals anything but the very highest qualities of crucible steels. These are very general statements, but they represent the writer's present more or less intuitive opinions, and only time can determine whether they are correct; for the fact that steels are of certain chemical compositions and give certain mechanical tests is not a final judgment, but the quality and length of service given in actual use. The special feature of the Heroult and Röchling-Rodenhauser types is that with an oxidising purification phosphorus can be eliminated to almost any extent that will pay, and after removing the slag, and forming another, by a reducing purification sulphur can similarly be removed.

The Kjellin induction furnace acts as a melter of materials much after the manner of the crucible, and has one advantage over the crucible in that there is no absorption of sulphur during melting. Recent experiments with covering slags specially calculated by the writer to give a minimum of change in composition during melting show, according to a student's preliminary analysis, compositions in the ingots practically equal to those by calculation from the constituents, a result better than expected, but still requiring thorough checking. The results at least serve as a text for one fact that must never be forgotten. The electric furnace, of whatever design, will not make good steel automatically. The same metallurgical skill required by the older processes must be expended on the proper killing and finishing of the steel by whatever type of electric furnace it is being melted, and the fact that in electric as in other furnaces bad steel may be made from good materials increases the difficulties of finding the exact place of any steel in the world's work. Several cases where the electric steel has been found unsuitable, especially in the earlier days, have been investigated, and it has been found that the steel has been wrongly made. In other cases no such explanation could be given. Recently I had a long talk with a man using large quantities of electric steel; he could get great purity, but no better mechanical tests; yet he found the electric steel gave a better life than his former steel, and so he used it. Here

1 Report presented at the Prrtsmouth meeting of the Britith Association (Section B) by Prof. Andrew McWilliam.

NO. 2 I93, VOL. 88 ? again another difficulty comes in as represented by the fact that I did not think his ordinary steel was specially well made.

One point of importance is that this production of electric steel has introduced a new competitor into the field by giving great impetus to the use of what is sometimes called white coal, namely, the great waterfalls, mostly far removed from coal; and much energy is now being used that formerly ran to waste, whilst the successful applica tion of electric power to the production of charcoal pigiron allows of a much reduced consumption of charcoal. The rapidly increasing price of charcoal in Sweden, owing, among other causes, to so much of the wood being used for making wood pulp for paper-making, is quite a serious situation, which this application of electric power may help to relieve.

The whole subject of electric iron-smelting and electric steel-melting is attracting much attention. Several books have been published on electric furnaces; and during 1909 and I9Io many interesting articles on the subject have appeared in the technical journals, and many papers have been read before the Iron and Steel Institute. At the autumn meeting of $1909 \mathrm{Mr}$. C. A. Ljungberg gave a paper on production of iron and steel by electric-smelting processes. He mentioned the Kjellin electric induction furnace at Gysinge, with which the writer had the pleasure of making with Mr. E. C. Ibbotson a full week's trial, as being still in work, making tool steel, special steels, selfhardening and high-speed steels, and others such as nickel and chromium steels. The paper dealt more in detail, however, with the successful experiments on smelting pigiron at Domnarfvet by electrical means, and the resulting saving in the proportion of charcoal used.

It will be only necessary merely to touch upon the various principles used in the construction of electric furnaces, as these are found in text-books and in the Proceedings of the Iron and Steel Institute. Having obtained an electric current, its energy may be converted into heat by putting a suitable resistance in its path, and the heat may be concentrated at any part of the circuit by making the resistance of other parts small in comparison. If the resistance be a solid or a liquid, then it is called resistanceheating; if a gas, arc-heating. If the liquid through which the current passes is decomposed by the current so that one kind of matter goes to one pole and another kind to the other pole, the liquid is called an electrolyte.

\section{Varieties of Electric Furnaces.}

The Stassano furnace is an independent arc furnace. Three carbon electrodes are used, between which arcs play, and the heat from the arc is merely used for heating the charge, partly by direct radiation and partly by reflection from the dome of the furnace.

The Héroult steel-melting furnace is a direct-arc type in which the charge forms one pole of the arc. Two vertical carbon electrodes come through the roof of the furnace and two arcs play, one between each electrode and the molten metal or slag beneath it, the current passing from one electrode through the metal or slag and up through the other electrode.

The Girod furnace, like the Héroult, is a direct-arc furnace, but one or more electrodes of like polarity are maintained above the bath, and soft steel pieces embedded in the hearth of the furnace are in direct contact with the molten metal for the negative electrode. These lower pole-pieces are water-cooled. Large quantities of ferrosilicon, ferro-chrome, \&c., as well as of ordinary carbon and special steels, are made in this furnace.

The Keller steel furnace is a direct-arc furnace, very much like the Herroult, only instead of two electrodes coming down into one cavity they come into separate cavities, which are joined by the molten material of the bath.

The Grönwall is of the arc type, and the current enters by two electrodes through the roof; and when once the bath is heated, so that the lining becomes a conductor, the current from both electrodes passes through the lining to a graphite block underneath, and hence to a common wire.

The Nathusius, like the Grönwall, is a combined arc and resistance furnace. It contains three vertical carbon electrodes, arranged at the apices of an equilateral triangle, 
and three steel electrodes similarly arranged in the bottom of the furnace, but covered by refractory material. Threephase current is used, and it is claimed that the current flows from one top electrode to the others, from one bottom electrode to the others, and from each top electrode to each bottom electrode.

Kjellin Induction Furnace.-In this furnace, an example of which is in the metallurgical laboratory of the University of Sheffield, and was shown working to the members of the British Association, the metal charge is placed in an annular hearth, almost like a steel-melting crucible in section, but in the form of a ring. The primary coil of twenty-four turns is placed in the centre round a core of taminated iron. The bath or ring of metal acts as a secondary circuit of a single turn, and the heat is thus produced in the charge itself without contact with electrodes. In the Frick furnace the primary coil is above the crucible, and in the Colby round the outside of the crucible.

The Röchling-Rodenhauser furnace is based on the Kjellin principle, but has an important addition. In its simplest form, for single-phase current, there are two grooves, or heating channels, corresponding to the annular crucible of the Kjellin, but these join to a central openhearth, the whole hearth forming a kind of figure 8. In the central open-hearth all the distinctly metallurgical operations take place, so that this form can be used for refining work, for which the Kjellin is not very suitable. Not only so, but a distinct secondary winding is provided in which a secondary current is induced, and these windings are joined to steel terminal plates which are embedded in the refractory material of the furnace at the ends of the central hearth. At high temperatures the refractory material becomes a conductor of electricity, and thus the currents induced pass through the bath in the central hearth, heating it still further.

There are many others, some only on paper; but these are the principal varieties that have been tried with any considerable degree of success. The loss in melting is an important point, and I am informed that this amounts to about $\mathrm{I} \frac{1}{2}$ per cent. in the Kjellin, about 4 to 5 per cent. in the Röchling-Rodenhauser, and 7 to 8 per cent. in arc furnaces.

In considering the present position of the electric steelmelting industry regard must be had to the numbers and capacities of the various types of furnaces in work, not in work, and being built, although a complete survey should also take account of the nature and quality of the materials being made, for a furnace making a ton of high-speed steel should obviously be credited with more importance in the commercial world than one making a ton of steel for rails. The progress in numbers and capacities and in output should also be considered. So far as one could ascertain, about June, 1910, there were about 118 furnaces of all types, of which 70 were in use, ro not working, and 38 being built. There were 77 of the arc furnaces recorded, of which 29 were credited as Héroult, 17 Girod, 13 Stassano, 6 Keller, and 9 others; besides one furnace at Domnarfvet, Sweden, for the production of 2500 tons of pig-iron per annum, with one in Norway and one at Trollhättan, Sweden, both in course of construction, and each designed to produce about 7500 tons of pig-iron annually. Of the Héroult furnaces, the total capacity per charge of those working was about 80 tons, and of those in course of construction about 50 tons. The Girod furnaces, the great competitors of the Héroult, were recorded at about 38 tons in work and 26 tons being built. Similarly, the figures for the Keller were I3 tons and 5 tons, and for the others 20 tons and 13 tons respectively.

Of the induction furnaces, the Kjellin furnaces erected totalled fourteen, with 35 tons capacity; the RöchlingRodenhauser fifteen, with 30 tons in work, $I$ ton not in work, and 17 tons capacity being built; all others about 18 tons in work. That gave a total capacity of about 250 tons for the arc furnaces and Ioo tons for the induction, or a grand total of $35^{\circ}$ tons per charge for all electric steelmelting furnaces. Pressure of other work has prevented me from getting the latest figures from all the firms making electric furnaces, but I have obtained these from the two most important firms, viz. the Herroult and the Kjellin and Röchling-Rodenhauser, and in this connection would record my best thanks to Mr. Donald F. Campbell and Mr. E. C.
Ibbotson, respectively, for their kind help and trouble in getting me this information. Comparing the Héroult furnaces only, as an example, we have seen that in June, Igro, there were twenty-nine of these furnaces with a capacity of 80 tons in work and 50 tons in course of erection, I30 tons in all; whilst about June, I9II, there were fortythree furnaces, with a total capacity of about $24^{2}$ tons

The output of electric steel in Germany, the United States, and Austria-Hungary in Igro amounted to almost 112,000 tons, which is an increase of 63,000 tons over the figures for 1909. These are the only countries for which the exact output of electric steel is published, but there is no doubt that the figures for Sweden, France, Belgium, and Italy would also show large gains. The increase will probably be more than maintained in I9II, as more than thirty new furnaces of various types should be started during the year, and many which only started towards the end of 1910 will put in a full year's work in I9II. England will also for the first time appear as a regular producer. Before the beginning of the present year the Héroult furnace at Edgar Allen's in Sheffield was the only arc one in steady operation. In January three Héroult furnaces were commenced in England: at Vickers' and Thos. Firth and Sons' in Sheffield, and at Lake and Elliott's in Braintree, Essex. A Grönwall furnace, for demonstration and manufacturing purposes, also started at about the same time in Sheffield; and the output of England for 19II should amount to about I3,000 tons. A 15 -ton Héroult furnace is to be erected at Skinningrove shortly, and is expected to turn out 200 tons per day. About the same period Kjellin induction furnaces have been working satisfactorily at Vickers and Jessop's in Sheffield and an experimental furnace at the University of Sheffield.

Great progress will be made in Germany with electric furnaces during the next year, when Héroult furnaces of 25 and 22 tons capacity are to be constructed. At present the largest size are the two 15 -ton Heroult furnaces at $\mathrm{S}$. Chicago and Worcester, belonging to the United States Steel Corporation, who have recently acquired the Heroult patents for America, and will probably erect several more furnaces shortly.

The electric furnace can be used either for melting scrap directly or in combination with some other form of furnace, in which case it simply acts as a refiner. The majority of the recent furnaces have been employed in this way, in conjunction either with Bessemer or open-hearth furnaces. The latter are usually of the basic tilting type, part of the charge being removed to the electric furnace after the pig is meited and the bulk of the phosphorus removed, leaving some phosphorus and the oxygen and sulphur to be eliminated by the electric furnace. In this case the time required for the electric furnace is from one hour to two hours, according to the degree of refining required and the original condition of the steel when removed from the basic furnace. The power used varies from 100 to $300 \mathrm{kw}$. hours per ton. When cold scrap is melted the time required is about six hours, and the power consumption said to be from $65^{\circ}$ to $75^{\circ} \mathrm{kw}$. hours: but really, all in, more probably 800 to 1000 per ton. Of the forty-four Herroult furnaces in operation or construction twenty-one are to melt scrap, twenty to take molten steel from the basic open-hearth, one from a Talbot furnace, and two from converters.

Electric furnaces are being employed in the following

(I) To replace crucibles. The gain is then one of cost of production.

(2) For foundries. Electric furnaces are being used in many foundries. At Georg Fischer's and Schaffhausen they are the only furnaces employed, and Lake and Elliott, of Braintree, are now making most of their steel electrically.

(3) To replace Swedish Bessemer steel, and for steel of axle and tyre quality.

(4) For weldless tubes. The Mannesmann Company has Héroult furnaces in Germany and Italy.

(5) In combination with Talbot furnaces. Owing to the fact that the heat need not be sufficiently great for teeming on transference to the electric furnace, the output of the Talbot and the life of the lining and roof are said

NO. 2 I93, VOL. 887 
to be largely increased. This will be the procedure at Skinningrove for making rails.

(6) For melting turnings, especially high-speed turnings. These make excellent scrap for the electric furnace.

Nickel scrap can be melted without any loss of nickel.

There are two aspects of the present position of a comparatively new industry. One is the progress made during the year, and an endeavour has been made to present that point of view. Another aspect is the actual state of the industry at present, and that can best be judged by the following two tables representing the furnaces, capacities, and kind of work done by all the furnaces under the care of the two principal firms already named. A very interesting item in the induction-furnace list is the entry representing the fact that the Kjellin furnace has been adopted for melting the metal for the manufacture of those delightful, though expensive, culinary vessels of pure nickel so much appreciated now.

List of Héroult Furnaces in Construction or Operation.

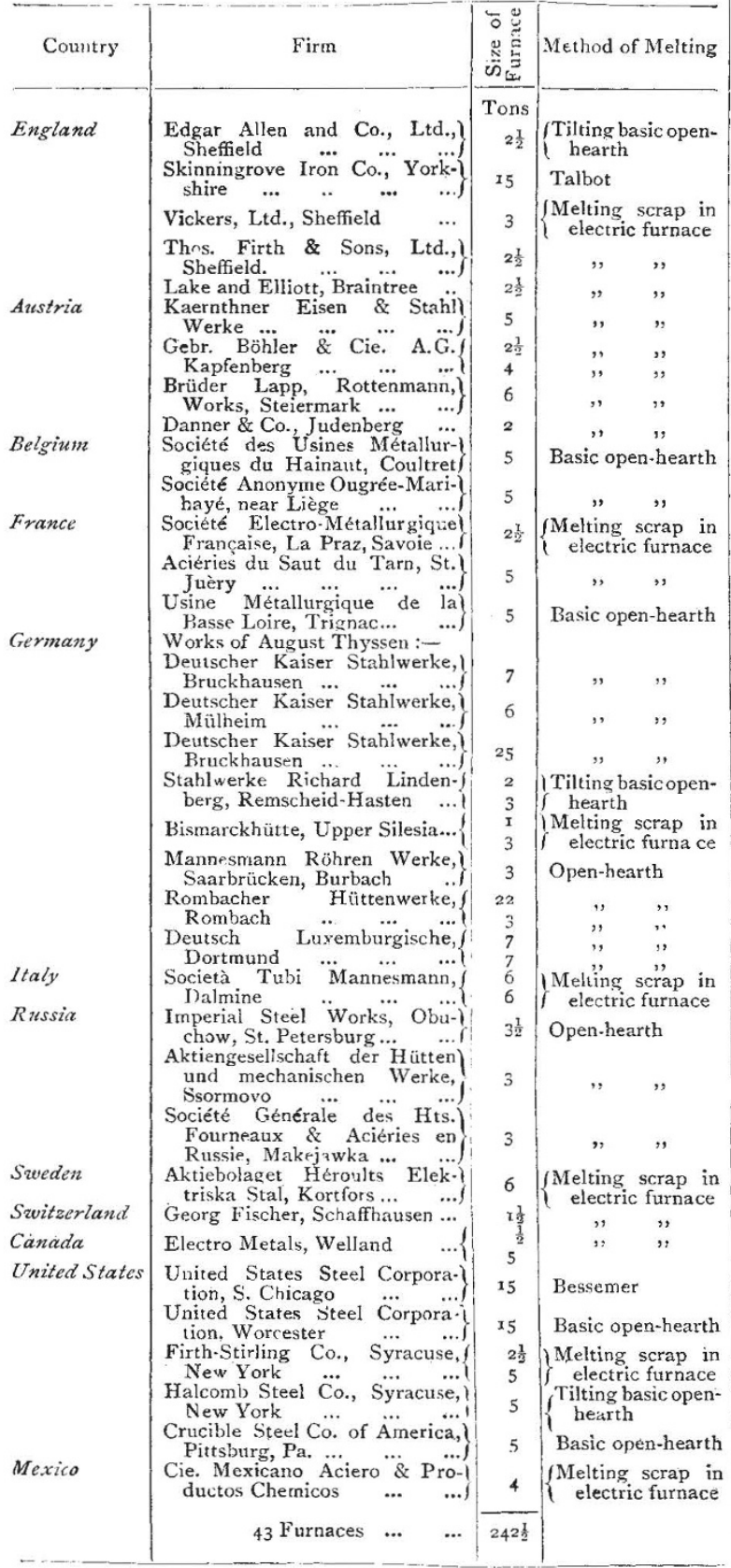

No. 2 I93, VOL. 88$]$

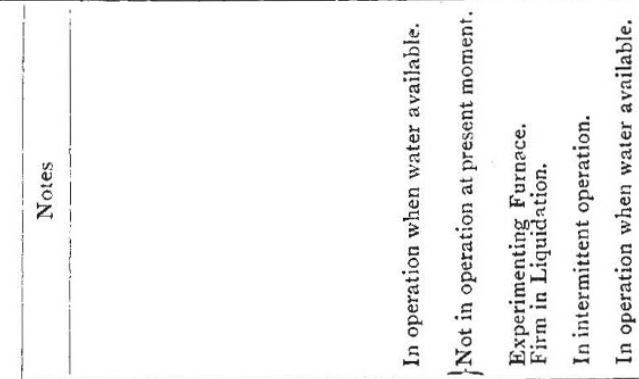

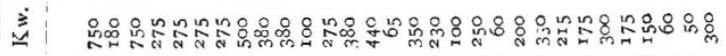

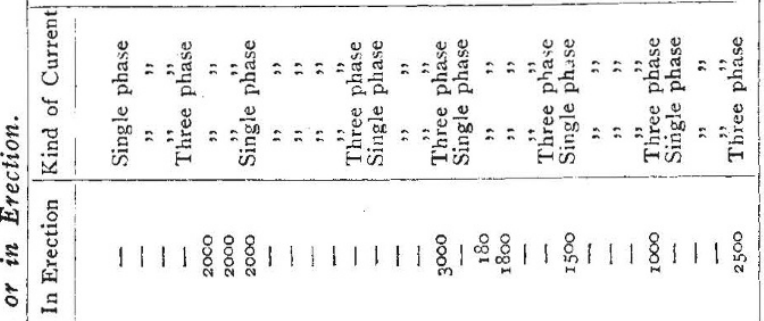

1111111111111111011001111111111

ఏ.

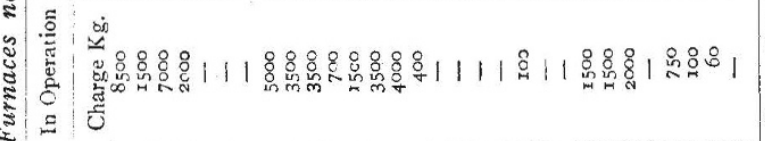

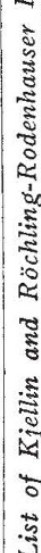

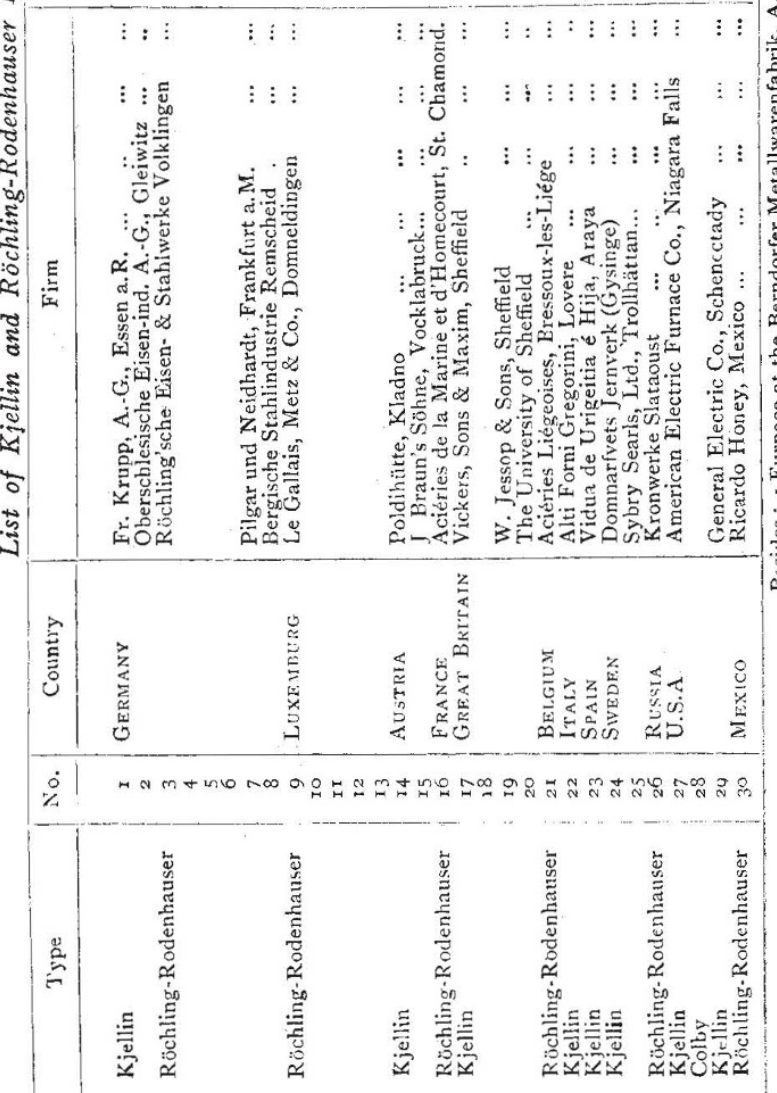

